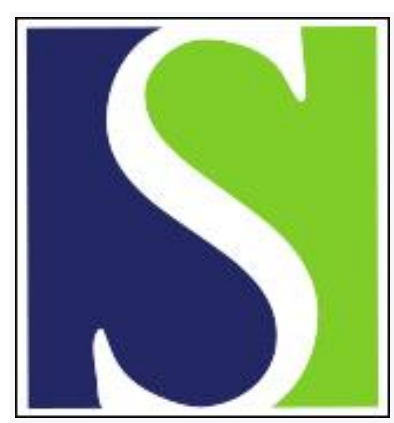

Scand J Work Environ Health 1987;13(1):32-36

https://doi.org/10.5271/sjweh.2084

Issue date: Feb 1987

Noise-induced hearing loss in relation to vibration-induced white finger in chain-saw workers.

by Miyakita T, Miura $\mathrm{H}$, Futatsuka M

This article in PubMed: www.ncbi.nlm.nih.gov/pubmed/3576142

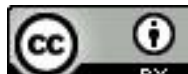




\title{
Noise-induced hearing loss in relation to vibration-induced white finger in chain-saw workers
}

\author{
by Takashi Miyakita, PhD, ${ }^{1}$ Hajime Miura, MD, ${ }^{1}$ Makoto Futatsuka, $M D^{2}$
}

\begin{abstract}
MIYAKITA T, MIURA H, FUTATSUKA M. Noise-induced hearing loss in relation to vibration-induced white finger in chain-saw workers. Scand $J$ Work Environ Health 13 (1987) 32-36. From the viewpoint of the etiologies of noise-induced permanent threshold shift (NIPTS) and vibration-induced white finger (VWF), the association between VWF and hearing loss was examined among 499 chain-saw workers who underwent a compulsory health examination for vibration syndrome. They were classified by age, duration of noise and vibration exposure, and the severity of VWF. The severity of VWF was evaluated according to the following criteria: (i) no prior history; (ii) VWF history, but symptoms had disappeared; (iii) VWF present but appearing rarely; (iv) frequent appearance of VWF (more than 20 times per winter season). In three age groups (ie, 40-49, 50-59, 60-69 years) with 5-9 years of exposure, the chainsaw workers with VWF had a significantly greater hearing loss at higher frequencies than those without VWF. However, in the 10- to 14-year exposure groups, a significant difference was not found between the VWF and non-VWF groups, except that the 50- to 59-year age groups showed a significant difference in mean age. It was suggested that interindividual differences in susceptibility to noise and vibration may be the reason for the synergistic effects of noise and vibration.
\end{abstract}

Key terms: forestry worker, hand-arm vibration, noise, synergistic action.

Forestry workers using chain saws are exposed to the risk of both vibration syndrome and noise-induced hearing loss. It has been reported that the hearing loss of workers with vibration-induced white finger (VWF) is severer than that of workers without $\operatorname{VWF}(7,8,18)$. The authors examined this relationship from the viewpoint of the etiologies of the noise-induced permanent threshold shift (NIPTS) and VWF. The interaction of hand-arm vibration and noise seems to lead to an increase in the prevalence of NIPTS among exposed workers. The reason for the synergistic action of vibration and noise on the NIPTS is still obscure. One possible cause may be that the sympathetic nervous tones created by hand-arm vibration severe enough to cause VWF may raise the vulnerability of the cochlea to noise through vasoconstriction in the inner ear (17).

In the present study subjects were classified according to the severity of VWF, age, and duration of noise and vibration exposure. Pure-tone air-conduction hearing levels were measured with an audiometer at frequencies of $0.5,1,2,3,4,6$, and $8 \mathrm{kHz}$ in $5-\mathrm{dB}$ steps.

\footnotetext{
Department of Hygiene, Kumamoto University Medical School, Kumamoto, Japan.

2 Department of Public Health, Kumamoto University Medical School, Kumamoto, Japan.
}

Reprint requests to: Dr T Miyakita, Department of Hygiene, Kumamoto University Medical School, Honjo 2-2-1, Kumamoto 860, Japan.

\section{Subjects and methods}

\section{Subjects}

The investigations were made in connection with a compulsory health examination of all operators of hand-held vibration tools working for the National Board of Forestry on the island of Kyushu in Japan. Five hundred and seventy men who had earlier had signs and symptoms of VWF and or peripheral neuropathy underwent compulsory health examinations for vibration syndrome in 1982 and 1983. From these 570 workers, 499 subjects were selected for the study. They had neither a history of occupational noise exposure other than that of chain saws nor a history of ear disease suggesting hearing abnormality, head injury, or the administration of drugs liable to affect hearing.

\section{Hearing measurement}

Pure-tone air-conduction hearing levels were measured with a diagnostic audiometer (RION AA-62) at frequencies of $0.5,1,2,3,4,6$, and $8 \mathrm{kHz}$ in $5-\mathrm{dB}$ steps. The audiometer was calibrated according to the Japanese standard JIS T1201-1963 (9) before the investigation. The background noise in the testing room was too high to allow the measurement of hearing level at low frequencies ( $\leq 1 \mathrm{kHz}$ ), but at $\geq 2 \mathrm{kHz}$ it was well within the limit specified in the standard ANSI S3.1-1977(1). Thus the hearing levels at 0.5 and $1 \mathrm{kHz}$ were omitted from the data analysis. None of the subjects had been exposed to tool noise for at least 48 $\mathrm{h}$ prior to the audiometric test. 


\section{Evaluation of vibration-induced white finger}

The workers completed a questionnaire on their state of health, medication, and symptoms. A medical history was taken, and a physical examination, always by the same doctor, was carried out concerning, especially, the symptoms and signs of VWF. A cold provocation test (hand immersion for $10 \mathrm{~min}$ in cold water at $10^{\circ} \mathrm{C}$ ) was performed. VWF was diagnosed when there was a history of blanching of the fingers. Other causes, including primary Raynaud's phenomenon, were ruled out on the basis of the history, examination, and results of routine laboratory tests. The severity of VWF was evaluated according to the following criteria: (i) no prior history of white finger; (ii) VWF history, but symptoms having disappeared more than three years ago; (iii) VWF present but ap- pearing rarely; (iv) frequent appearance of VWF (more than 20 times per winter season). In our classification, the frequency of VWF was of greater importance than the number of fingers afflicted by VWF.

\section{Chain-saw noise and vibration}

We analyzed the physical characteristics of vibration and noise during the operation of various chain saws (76 samples). The peak values of the vibration acceleration levels ranged from 8 to $14 \mathrm{~m} / \mathrm{s}^{2}$, and the main frequency band ranged from 100 to $160 \mathrm{~Hz}$. The peak values of the sound pressure level ranged from 105 to $118 \mathrm{~dB}(\mathrm{~A})$. Figures 1 and 2 show the noise and vibration spectra, respectively, for one of the most common chain saws (Shingu SP500D) in the last decade.

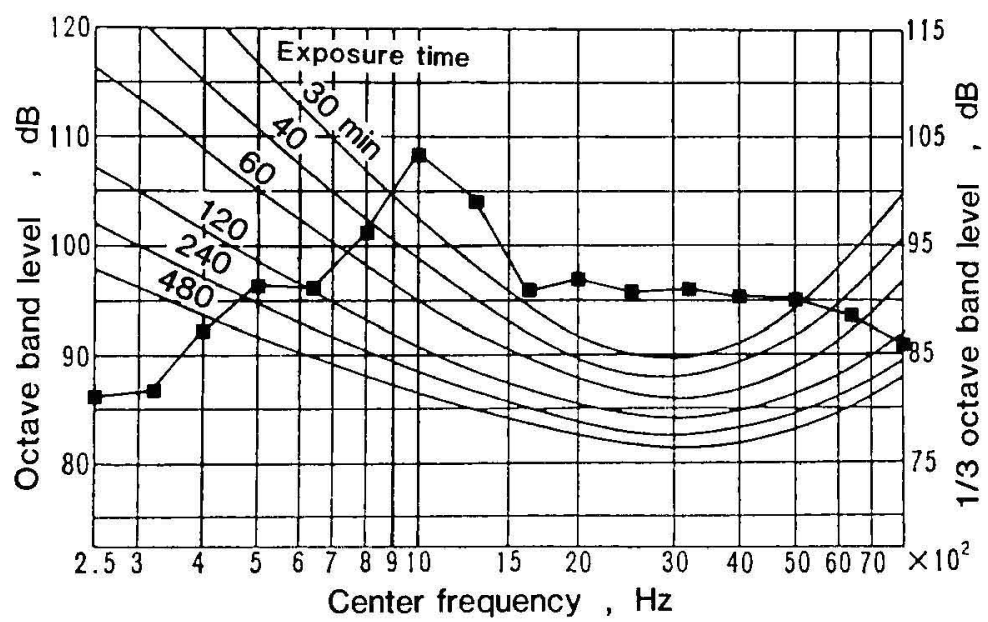

Figure 1. Noise spectrum from a chain saw (Shingu SP500D) analyzed in the one-third octave band, including the curves of permissible criteria for steadystate noise exposure recommended by the Japan Association of Industrial Health.

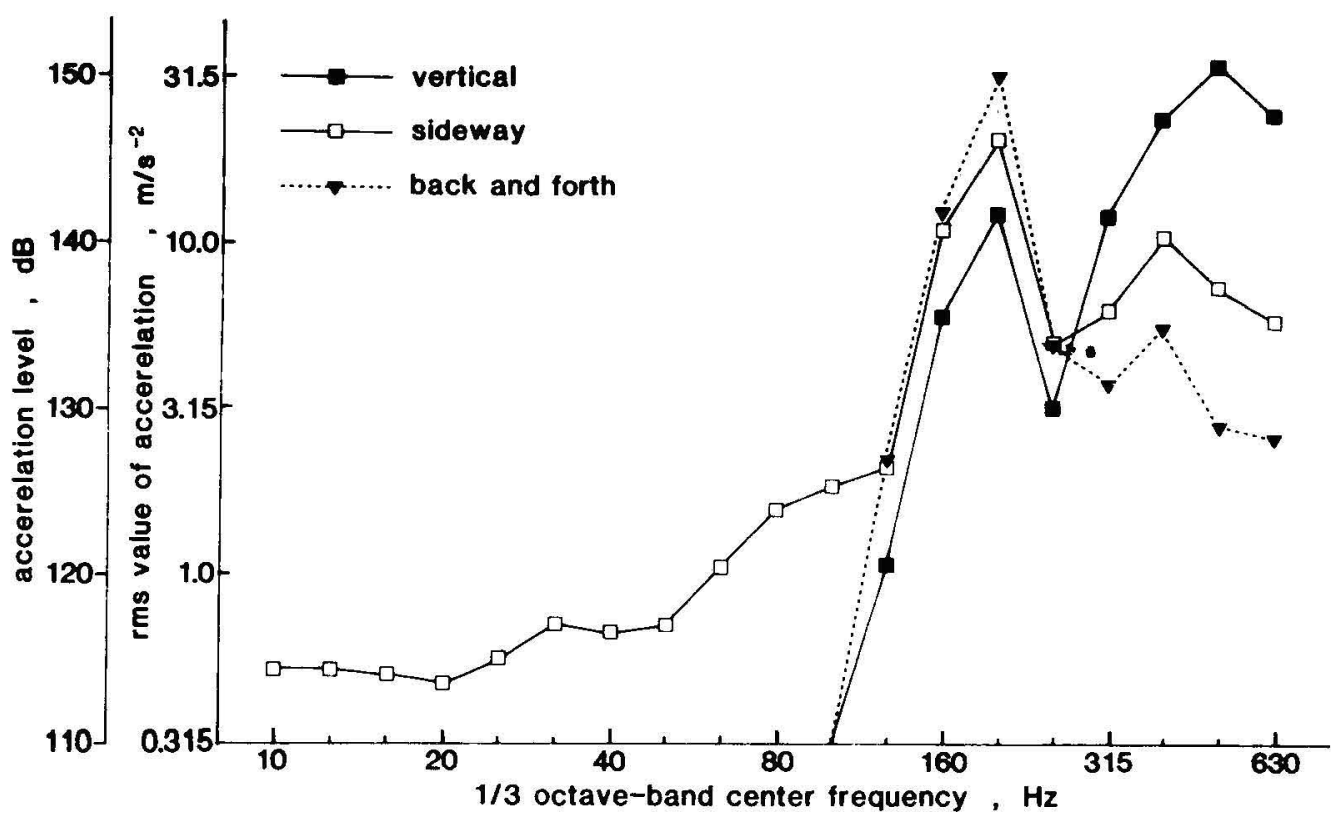

Figure 2. Vibration spectrum from a chain-saw handle (Shingu SP500D) analyzed in the one-third octave band. (rms = root mean square) 


\section{Statistics}

The significance of the differences between the groups was tested with Student's t-test for independent samples. Welch's test (20) was applied when the sample variances differed considerably. Two-sided testing was used.

\section{Results}

Table 1 shows the mean values and standard deviations of the age and duration of exposure of the workers by the severity of VWF. There were no remarkable differences in age and duration of exposure among the different VWF groups, except that the workers exposed for 10 to 14 years in the 50- to 59-year age group differed significantly with respect to mean age.

Because the sample sizes for each of the stages of VWF were not so large, VWF severity groups 1 and 2 were combined, as were VWF severity groups 3 and 4. Group $3+4$ had significantly greater hearing losses than group $1+2$ in every age group exposed from five to nine years, as shown in figure 3. For this range of exposure duration, significant differences were observed for the following frequencies and age groups: at $6 \mathrm{kHz}(\mathrm{p}<0.1)$ in the 40 - to 49 -year age group; at $3 \mathrm{kHz}(\mathrm{p}<0.01)$ and $4 \mathrm{kHz}(\mathrm{p}<0.05)$ in the 50 to 59-year age group; and at $4 \mathrm{kHz}(\mathrm{p}<0.05)$ and $6 \mathrm{kHz}(\mathrm{p}<0.05)$ in the 60- to 69-year age group. However, as shown in figure 4; in the 10- to 14-year exposure groups, there were no significant differences in hearing level between VWF severity group $1+2$ and group $3+4$, except that of the 50- to 59-year age groups, for which there was also a significant difference in mean age (table 1).

\section{Discussion}

Although there are many reports of the hazardous effects of noise on hearing, the mechanism of NIPTS is still obscure $(2,4,5)$. A great concern to us is (i) that the relationships between temporary threshold shift and transient cellular changes that occur in the cochlea are not yet understood and (ii) that the extent of the temporary threshold shift poorly predicts the extent of NIPTS in individual subjects. It has been suggested that many factors, eg, direct mechanical destruction, metabolic exhaustion, vascular changes, and ionic changes, compete in causing acoustic damage to the cochlea. From the viewpoint of determining the mechanisms of NIPTS and that of establishing permissible criteria for noise exposure, it would be important to know whether vibration-induced dysfunction in peripheral circulation is also reflected in cochlear functions, ie, whether the combination of noise and vibration produces an exaggerated NIPTS in subjects with VWF.

In the evaluation of the association between hearing loss and VWF, 499 subjects were classified into two groups, a non-VWF group (severity group $1+2$ ) and a VWF group (severity group $3+4$ ). Among the subjects (with a past history of VWF) classified into group 2 , the disorder seemed to be relatively light and to be reversible. Thus we considered it reasonable to treat them together with group 1 (no prior history of VWF).

In three age groups (ie, 40-49, 50-59, 60-69 years) with five to nine years of exposure, we found that chain-saw workers with VWF had significantly greater hearing losses at higher frequencies than those without VWF. This difference in NIPTS agrees well with results reported earlier $(7,8,18)$. However, in the 10- to 14-year exposure groups, we could not find a significant difference between the VWF and non-VWF groups.

A large individual difference in noise susceptibility $(12,13,14)$ is well known, that is, given two individuals exposed to the same noise for the same duration, one may retain a hearing level that is almost normal while the other may sustain a significant hearing loss (15). However, Yamamoto (21) indicated that average trend curves of hearing loss (the value after "presbycusis" correction) in relation to exposure time (year) roughly fit the formula $y=L\left(1-e^{-k t}\right)$, where $y$ signifies the mean threshold shift induced by exposure time $t$, and $k$ and $L$ are constants. In the present study the NIPTS values after "presbycusis" correction seemed to reach a plateau during approximately 10 or 15 years of exposure, although this occurrence depended on the ex-

Table 1. Means and standard deviations of the ages and length of exposure of the workers divided into groups according to age, duration of exposure, and severity of vibration-induced white finger (VWF).

\begin{tabular}{|c|c|c|c|c|c|c|c|c|c|c|c|c|c|c|c|c|}
\hline \multirow{4}{*}{$\begin{array}{l}\text { Age group } \\
\text { (years) }\end{array}$} & \multicolumn{8}{|c|}{$5-9$ years of exposure } & \multicolumn{8}{|c|}{$10-14$ years of exposure } \\
\hline & \multicolumn{4}{|c|}{ VWF severity $1+2^{a}$} & \multicolumn{4}{|c|}{ VWF severity $3+4^{b}$} & \multicolumn{4}{|c|}{ VWF severity $1+2^{a}$} & \multicolumn{4}{|c|}{ VWF severity $3+4^{b}$} \\
\hline & \multicolumn{2}{|c|}{$\begin{array}{c}\text { Age } \\
\text { (years) }\end{array}$} & \multicolumn{2}{|c|}{$\begin{array}{c}\text { Exposure } \\
\text { (years) }\end{array}$} & \multicolumn{2}{|c|}{$\begin{array}{c}\text { Age } \\
\text { (years) }\end{array}$} & \multicolumn{2}{|c|}{$\begin{array}{c}\text { Exposure } \\
\text { (years) }\end{array}$} & \multicolumn{2}{|c|}{$\begin{array}{c}\text { Age } \\
\text { (years) }\end{array}$} & \multicolumn{2}{|c|}{$\begin{array}{c}\text { Exposure } \\
\text { (years) }\end{array}$} & \multicolumn{2}{|c|}{$\begin{array}{c}\text { Age } \\
\text { (years) }\end{array}$} & \multicolumn{2}{|c|}{$\begin{array}{c}\text { Exposure } \\
\text { (years) }\end{array}$} \\
\hline & Mean & $\mathrm{SD}$ & Mean & SD & Mean & SD & Mean & SD & Mean & $\mathrm{SD}$ & Mean & SD & Mean & SD & Mean & SD \\
\hline $\begin{array}{l}40-49 \\
50-59 \\
60-69\end{array}$ & $\begin{array}{l}46.0 \\
54.0 \\
63.9\end{array}$ & $\begin{array}{l}2.6 \\
2.9 \\
2.9\end{array}$ & $\begin{array}{l}7.3 \\
7.5 \\
6.8\end{array}$ & $\begin{array}{l}1.4 \\
1.4 \\
1.3\end{array}$ & $\begin{array}{l}47.0 \\
54.3 \\
65.2\end{array}$ & $\begin{array}{l}2.6 \\
2.8 \\
2.4\end{array}$ & $\begin{array}{l}7.1 \\
7.2 \\
7.1\end{array}$ & $\begin{array}{l}1.4 \\
1.2 \\
1.5\end{array}$ & $\begin{array}{l}46.2 \\
53.6 \\
63.7\end{array}$ & $\begin{array}{l}2.6 \\
2.6 \\
2.3\end{array}$ & $\begin{array}{l}11.6 \\
11.8 \\
11.8\end{array}$ & $\begin{array}{l}1.4 \\
1.5 \\
1.3\end{array}$ & $\begin{array}{l}45.9 \\
55.2^{*} \\
64.6\end{array}$ & $\begin{array}{l}2.4 \\
2.8 \\
3.2\end{array}$ & $\begin{array}{l}11.5 \\
11.6 \\
12.0\end{array}$ & $\begin{array}{l}1.7 \\
1.4 \\
1.4\end{array}$ \\
\hline
\end{tabular}

a 1 = no prior history of VWF, 2 = VWF history, but symptoms having disappeared more than three years ago.

b $3=$ VWF present but appearing rarely, $4=$ frequent appearance of VWF (more than 20 times per winter season).

* $p<0.05$ (versus VWF severity group $1+2$ ). 

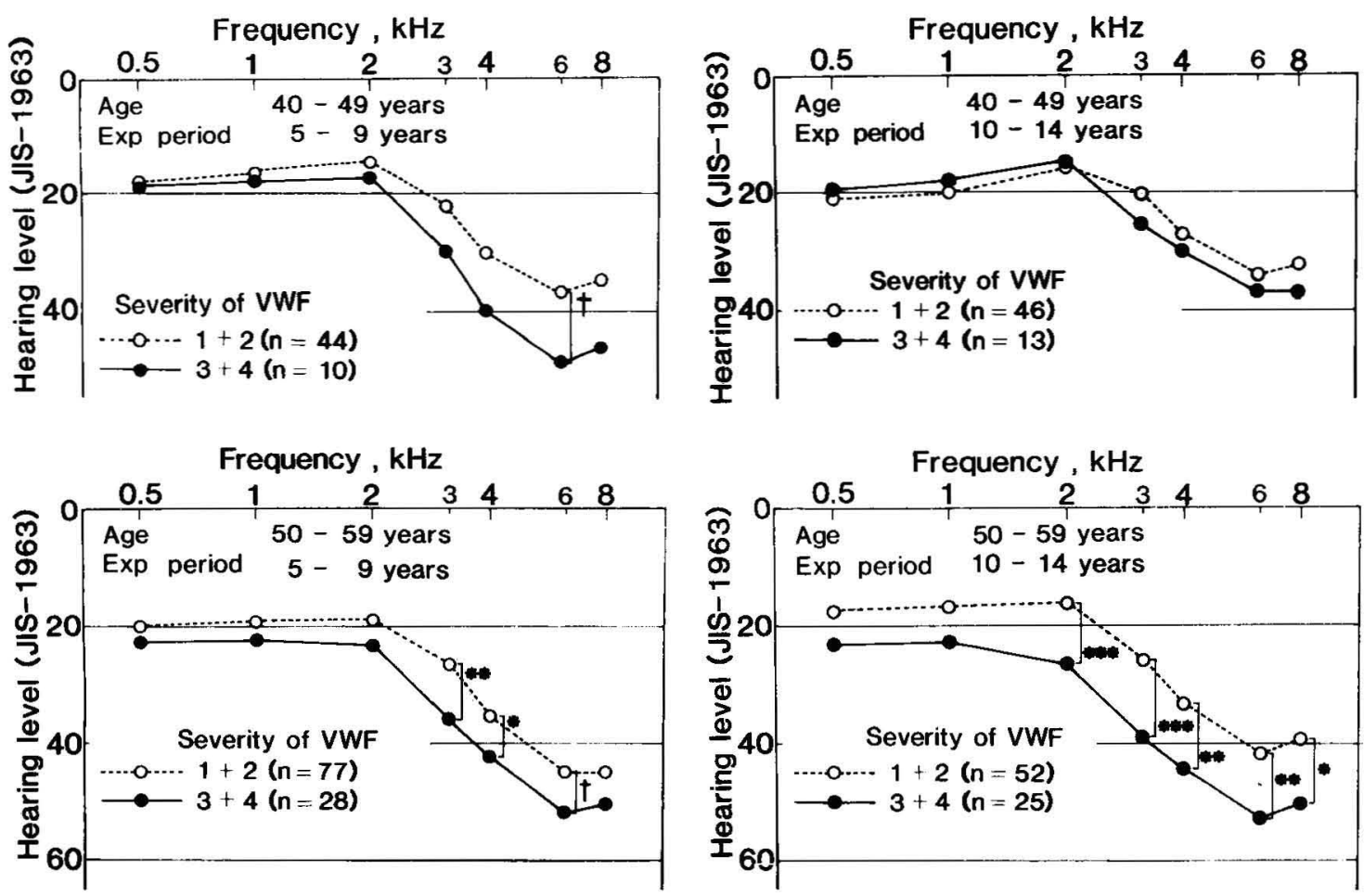

\section{Frequency, $\mathrm{kHz}$}

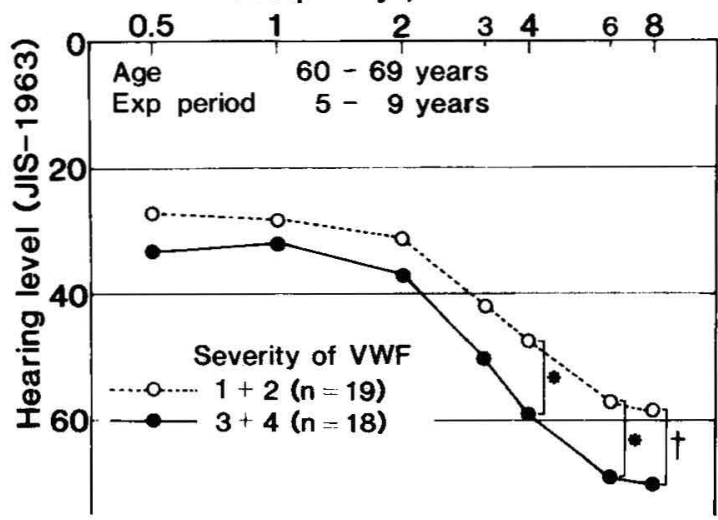

Figure 3. Mean audiographic values of the workers currently suffering (severity group $3+4$ ) and those not currently suffering (severity group $1+2$ ) from vibration-induced white fin ger (VWF) in the 5- to 9-year exposure group $\left({ }^{*} p<0.05\right.$ ${ }^{*} p<0.01$, $\left.\mathrm{p} p<0.1\right)$. (Exp = exposure)

posure level and the frequency of the noise. These findings may provide one possible explanation for the fact that no significant difference was found between the VWF and non-VWF groups with the $10-14$ years of exposure.

Futatsuka \& Ueno (3) also derived a cumulation curve for the latency period of VWF, which was divided into short ( $<5$ years), medium ( $5-12$ years), and long ( $>12$ years) exposure duration periods, as a result of a longitudinal study which was undertaken to evaluate changes in the prevalence of VWF during 1956-1980 among 1456 forestry workers. They sug-

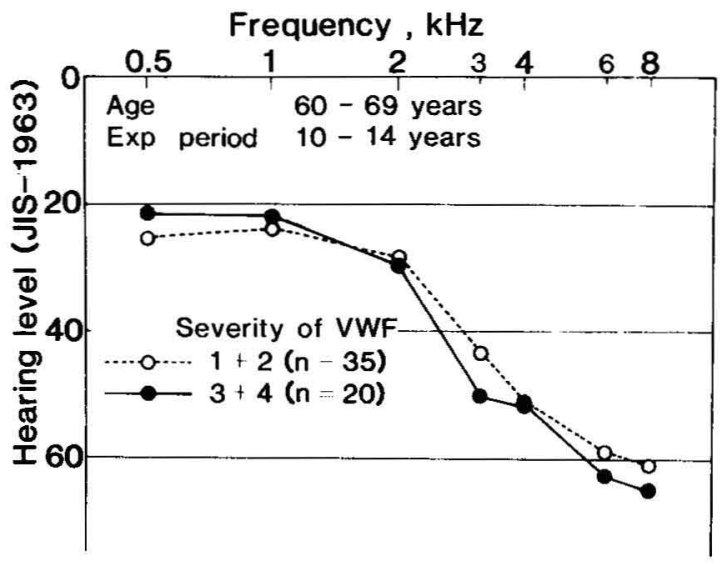

Figure 4. Mean audiographic values of the workers currently suffering (severity group $3+4$ ) and those not currently suffering (severity group $1+2$ ) from vibration-induced white finger (VWF) in the 10. to 14-year exposure group $\left({ }^{*} p<0.05\right.$, $\left.{ }^{\star *} p<0.01,{ }^{* * *} p<0.005\right)$. (Exp $=$ exposure)

gested that some differences in the susceptibility to vibration in the subjects may be reflected in these results. In this population, $85 \%$ of the workers with VWF had a latency period of 10 years or less.

With these findings taken into account, the present result, which suggests some relationship between hearing loss and disorders in peripheral circulation, is very interesting. Concerning an effect of noise on microcirculation in the cochlea, participation of the sympathetic nervous system has been suggested on the basis of data obtained in animal experiments $(6,10$, $11,16,19)$. But no relationships between exposure to 
hand-arm (local) vibration and cochlear microcirculation have yet been found. When noise and local vibration act on the ear and the hand-arm simultaneously, whether or not the reaction of the microcirculation in the cochlea is analogous to that in the digital vessels is still unclear.

\section{References}

1. American National Standards Institute. ANSI criteria for permissible ambient noise during audiometric testing. Section 3.1. New York, NY 1977.

2. Axelsson A. Diagnosis and treatment of occupational noise-induced hearing loss. Acta Oto Laryng Suppl 360 (1979) 86-87.

3. Futatsuka M, Ueno T. Vibration exposure and vibrationinduced white finger due to chain saw operation. J Occup Med 27 (1985) 257-264.

4. Harmernik RP, Henderson D, Salvi R, ed. New perspectives on noise-induced hearing loss. Raven Press, New York, NY 1982.

5. Henderson D, Harmernik RP, Dosanjh DS, Mills JH, ed. Effects of noise on hearing. Raven Press, New York, NY 1976.

6. Hultcrantz E. The effect of noise on cochlear blood flow in the conscious rabbit. Acta Physiol Scand 106 (1979) $29-37$.

7. Iki M. Noise-induced deafness among forestry workers using vibrating tools (Part 2): An association between digital circulatory disturbance and hearing loss. J Sci Labour 60 (1984) 215-222.

8. Iki M, Kurumatani N, Hirata K, Moriyama T. An association between Raynaud's phenomenon and hearing loss in forestry workers. Am Hyg Assoc J 46 (1985) $509-513$.

9. Japanese Industrial Standards. Diagnostic audiometers. Tokyo 1963. (JIS T 1201-1963).

10. Koide Y, Yoshida M, Konno M, Nakano Y, Yoshikawa $Y$, Nagaba $M$, Morimoto $M$. Some aspects of the biochemistry of acoustic trauma. Ann Otol Rhinol Laryngol 69 (1960) 661-698.

11. Mishary G, Shinabarger EW, Arnold JE. Changes in cochlear endolymphatic oxygen availability, action potential and microphonics during and following asphyxia, hypoxia and exposure to loud sounds. J Acoust Soc Am 30 (1958) $701-704$.

12. Miyakita T, Miura H. Study on an evaluation index for noise susceptibility: I Estimation of critical bandwidth in acoustic reflex. Int Arch Occup Environ Health 55 (1985) 285-293.

13. Miyakita T, Miura $\mathbf{H}$. Study on an evaluation index for noise susceptibility: II Reduction of $\mathrm{ART}_{\mathrm{Ik}}-\mathrm{ART}_{\mathrm{WN}}$ and critical bandwidth in acoustic reflex. Int Arch Occup Environ Health 55 (1985) 295-303.

14. Miyakita T, Miura H, Yamamoto T. Evaluation of noise susceptibility: Effects of noise exposure on acoustic reflex. Int Arch Occup Environ Health 52 (1983) 231-242.

15. Møller AR. Noise as a health hazard. In: John ML, ed. Public health and preventive medicine. Appleton Century Crofts, New York, NY 1980.

16. Perlman HB, Kimura R. Cochlear blood flow in acoustic trauma. Acta Oto Laryng 54 (1962) 99-110.

17. Pyykkö I, Starck J. Vibration syndrome in the etiology of occupational hearing loss. Acta Oto Laryng Suppl 386 (1982) $296-300$.

18. Pyykkö I, Starck J, Färkkilä M, Hoikkala M, Korhonen $\mathrm{O}$, Nurminen $M$. Hand-arm vibration in the aetiology of hearing loss in lumberjacks. $\mathrm{Br} \mathrm{J}$ Ind Med 38 (1981) 281-289.

19. Sita T. Intense tone and endolymphatic potential [in Japanese]. Audiology (Japan) 8 (1965): 1-7, 23-30.

20. Welch BL. The significance of the difference between two means when the population variances are unequal. Biometrika 29 (1938) 350-362.

21. Yamamoto $T$. The effects of industrial noise on hearing acuity and frequency-dependent standard for noise tolerance. Jpn J Nation's Health 25 (1956) 68-119.

Received for publication: 4 March 1986 